\title{
SERUM CYSTATIN C AS A BIOMARKER OF KIDNEY DYSFUNCTION IN PATIENTS WITH ADVANCED CIRRHOSIS
}

\author{
Afaf Aly Masoad ${ }^{1}$, Hany Mansour Khalil Dabbous ${ }^{1}$, Iman Mohamed Fawzy Montasser ${ }^{1}$, \\ Mohammed Sobhi Hassan ${ }^{2}$, Ramy Mohamed Ahmed ${ }^{3}$ and \\ Ahmed Mohamed El-Sayed Radwan ${ }^{1}$
}

Tropical Medicine, Radio

Diagnosis and Clinical

Pathology Departments

Faculty of Medicine, Ain

Shams University, Cairo, Egypt

\section{Corresponds:}

Ahmed Mohamed El-Sayed

Radwan

e.male:

doca7mad@yahoo.com,

Tel.: 01002751333

Receved: 18/2/2019

Accepted: 20/3/2019

\begin{abstract}
Background: Liver cirrhosis (LC) is associated with considerably high morbidity and mortality rates. Disturbed renal function is among the main complications of liver cirrhosis, frequently accompanying its later stages. It is related to poorer prognosis, especially if it has resulted from acute complications (sepsis) or has followed liver transplantation. Acute renal failure $(A R F)$ is relatively common - it occurs in approximately $20 \%$ of hospitalized patients with liver cirrhosis and includes prerenal azotemia, acute tubular necrosis and hepatorenal syndrome (HRS). With the progression of liver cirrhosis and portal hypertension, the renal dysfunction usually evolves to HRS, which is associated with high mortality rate, especially type I HRS.
\end{abstract}

Aim of the Work: Assessment of the role of Cystatin $C$ as a biomarker in renal dysfunction in patients with end stage liver disease.

Patients and Methods: This study was conducted in Tropical Medicine Department, Ain-Shams University and ain shams center for organ transplantation (ASCOT). This study included 60 patients with End Stage Liver Disease (ESLD) and 30 healthy subjects as control group. Patients groups: Group I: 30 patients ESLD, with renal impairment. Group II: 30 patients ESLD, without renal impairment. All patients were subjected to: complete blood count, liver function tests, kidney function tests, 24 hours urinary proteins, bleeding profile.

Results: The current study was conducted in Tropical Medicine Department at Ain Shams University, and Ain Shams Center for Organ Transplantation (ASCOT). Our study included 90 candidates, 60 patients with End Stage Liver Disease (ESLD), whom were further divided into group I of 30 patients ESLD, with renal impairment and group II of 30 patients ESLD, without renal impairment, and a third group of 30 healthy persons. Cystatin $C$ level was measured in all candidates in the three groups to assess its role as a biomarker in renal dysfunction in patients with end stage liver disease on the waiting list for liver transplantation.

Conclusion: Creatinine clearance was found to be significantly lower in ESLD patients with and without renal impairment in comparison to control group. It was also significantly lower in ESLD patients with renal impairment in comparison to ESLD patients without renal impairment. Cystatin $C$ level was found to be significantly lower in ESLD patients with and without renal impairment in comparison to control group. It was also significantly lower in ESLD patients with renal impairment in comparison to ESLD patients without renal impairment.

Keywords: Serum Cystatin C, Kidney Dysfunction, Advanced Cirrhosis, Liver cirrhosis 


\section{INTRODUCTION:}

Liver cirrhosis (LC) is associated with considerably high morbidity and mortality rates. Disturbed renal function is among the main complications of liver cirrhosis, frequently accompanying its later stages. It is related to poorer prognosis, especially if it has resulted from acute complications (sepsis) or has followed liver transplantation $^{(1)}$.

Acute renal failure (ARF) is relatively common - it occurs in approximately $20 \%$ of hospitalized patients with liver cirrhosis and includes prerenal azotemia, acute tubular necrosis and hepatorenal syndrome (HRS). With the progression of liver cirrhosis and portal hypertension, the renal dysfunction usually evolves to HRS, which is associated with high mortality rate, especially type I $\mathrm{HRS}^{(2)}$.

The majority of causes of RF in liver cirrhosis are functional - resulting from alterations in hemodynamics, renal autoregulatory mechanisms and cardiac function. Acute kidney injury is characterized by elevation of serum creatinine levels $\geq 50 \%$ of the baseline or $\geq$ $0.3 \mathrm{mg} / \mathrm{dl}(\geq 26.4 \mu \mathrm{mol} / \mathrm{l})$ for less than 48 hours. Chronic renal disease is present if the value of the (eGFR), calculated by the MDRD 6 formula is $<60 \mathrm{ml} / \mathrm{min}$ for more than 3 months ${ }^{(3)}$.

New early markers of acute renal injury -serum gelatinase-associated neutrophil lipocalin (sNGAL) and urine markers: gelatinase-associated neutrophil lipocalin (uNGAL), interleukin-18 (IL-18) and kidney injury molecule-1 (KIM-1), require complex methodology and further investigation on their efficacy ${ }^{(4)}$.

Doppler ultrasonography may also be used as an early diagnostic method for renal dysfunction. Since main causes of ARF in liver cirrhosis are prerenal failure and HRS, renal biopsy is rarely necessary, while precutaneous biopsy is related to increased risk of hemorrhages ${ }^{(5)}$.

Isotope determination of GFR is a reliable method, especially in decreased RF or variations in the muscle mass. It is more practical in comparison with inulin clearance - requires a single application and diuresis measurement is not needed ${ }^{(6)}$.

Creatine is produced in the liver, stored in skeletal muscles, where is phosphorilated to creatinine. Its concentrations are affected by some extra renal factors such as weight, race, age, gender, diet (protein intake), transformation of creatine into creatinine, level of hydration, as well as the overall organism storage of creatine (overall muscle mass) ${ }^{(7)}$.

Impaired liver function, Protein-poor diet and reduction in muscle mass, Serum creatinine increase leads to intensification of its tubular secretion, edematous state, and use of nephrotoxic drugs, such as cephalosporines. All lead to false low serum creat in cirrhotics. ARF is usually developed on the basis of complications like variceal bleeding, spontaneous bacterial peritonitis or sepsis - conditions related to increased tubular creatinine excretion ${ }^{(8)}$.

Cystatin $\mathrm{C}$ is a $13.3 \mathrm{kDa}$ (low molecular weight) protein, representative of cysteinprotease inhibitors. It is produced by all nucleus-containing cells with constant speed, is freely filtrated through the glomerules, is entirely reabsorbed and catabolized in the proximal tubular cells, does not have tubular secretion and reabsorption back into circulation. It is not influenced by inflammatory or malignant diseases, age, gender, muscle mass, diet, bilirubine and BMI (body mass index), and does not interfere with bilirubin ${ }^{(9)}$.

Cys C better correlates with GFR compared to creatinine, it is more sensitive for the diagnosis of mild decrease of GFR $(60-90 \mathrm{ml} / \mathrm{min} / 1.73 \mathrm{~m} 2)$ and is a better early predictor of creatinine in ARF. Its 
disadvantages compared to creatinine are related to higher test price and need of standardization. Data for the dependence of its levels on advanced age (especially $>50$ yrs), male gender, overweight, height, smoking and higher C-reactive protein levels, malignant diseases and some drugs (corticosteroids, ACE-inhibitors) are disputable ${ }^{(9)}$.

In a study on 89 patients with liver cirrhosis and ascites, only the serum CysC correlates well with the GFR scintigraphically determined by $99 \mathrm{mTc}-\mathrm{DTPA}$ clearance, its values being the only independent predictor of significant kidney injury. It is a good predictor of ARF, HRS and the mortality in patients with liver cirrhosis with or without ascites and with normal creatinine levels ${ }^{(10)}$.

\section{AIM OF THE WORK:}

Assessment of the role of Cystatin $\mathrm{C}$ as a biomarker in renal dysfunction in patients with end stage liver disease.

\section{PATIENTS AND METHODS:}

This study was conducted in Tropical Medicine Department, Ain Shams University and Ain Shams Center for organ transplantation (ASCOT).

\section{Patients:}

This study included 60 patients with End Stage Liver Disease (ESLD) and 30 healthy subjects as control group.

\section{Patients groups:}

1. Group I: 30 patients ESLD, with renal impairment.

2. Group II: 30 patients ESLD, without renal impairment.

\section{Inclusion criteria:}

1. Adult Egyptian patients (age: 18yrs$60 \mathrm{yrs})$.
2. $\operatorname{ESLD}($ MELD $>12)$.

3. HCV related end stage liver disease.

4. Renal impairment (creat $>1.5 \mathrm{mg} / \mathrm{dl}$, GFR $<60 \mathrm{ml} / \mathrm{min}$ ) in Group I.

5. No renal impairment (creat $<1.5 \mathrm{mg} / \mathrm{dl}$, GFR $>60 \mathrm{ml} / \mathrm{min}$ ) in Group II.

6. Informed consent.

\section{Exclusion criteria:}

1. End Stage Renal Disease (GFR $<20 \mathrm{ml} /$ $\min$ ).

2. Refuse to participate in the study.

3. Other causes of liver disease rather than $\mathrm{HCV}$.

\section{METHODS:}

All patients were subjected to:

1. Full history taking and thorough clinical examination

2. Laboratory investigations:

- Complete Blood Count (CBC), erythrocyte sedimentation rate (ESR) and $C$ reactive protein (CRP).

- Liver Function Tests (AST, ALT, S. Albumin, total protein, Bilirubin t\&d, Alkaline Phosphatase, $\gamma$ GT).

- Kidney Function Tests (S.Creat, BUN, $\mathrm{Na}, \mathrm{K}, \mathrm{Ca}$, Phosph., Mg, Choloride, Uric Acid).

- 24 hours urinary proteins and creat clearance calculated by Cockroft-Gault Formula.

- Bleeding profile: PT, PTT, INR, and prothrombin concentration.

- Fasting blood sugar.

- Tumor markers: AFP.

- Cystatin C by ELISA.

- Viral markers:

1) $\mathrm{HCV} \mathrm{Ab}$.

2) HBs Ag.

\section{Radiological investigations}


- Pelvi-Abdominal Ultrasound, and Renal Duplex

- Renal Isotope scan

\section{Cystatin C:}

\section{Preparation of samples:}

Samples were 400x diluted with the Dilution Buffer just prior to the assay in two steps as follows:

- Dilution A (10x): $10 \mathrm{ml}$ of sample was added into $90 \mathrm{ml}$ of Dilution Buffer. Mix well (not to foam). Vortex is recommended.
- Dilution B (40x): Add $10 \mathrm{ml}$ of Dilution A into $390 \mathrm{ml}$ of Dilution Buffer to prepare final dilution (400x), Mixed well (not to foam).

\section{Statistical Analysis}

Data were collected, revised, coded and entered to the Statistical Package for Social Science (IBM SPSS) version 23. The quantitative data were presented as mean, standard deviations and ranges when their distribution found parametric and median with inter-quartile range (IQR) when their distribution found non parametric while qualitative data were presented as number and percentages.

\section{RESULTS}

Table (1): Comparison between control group and patients subgroups regarding demographic data

\begin{tabular}{|c|c|c|c|c|c|c|c|c|c|c|}
\hline & $\begin{array}{l}\text { Control } \\
\text { group }\end{array}$ & $\begin{array}{c}\text { ESLD } \\
\text { without } \\
\text { renal } \\
\text { impairment }\end{array}$ & $\begin{array}{c}\text { ESLD } \\
\text { with renal } \\
\text { impairment }\end{array}$ & \multirow[t]{2}{*}{$\begin{array}{c}\text { Test } \\
\text { value }\end{array}$} & \multirow[t]{2}{*}{$\begin{array}{c}\text { P- } \\
\text { value }\end{array}$} & \multirow[t]{2}{*}{$\begin{array}{c}\text { Sig } \\
\text {. }\end{array}$} & \multirow[t]{2}{*}{ P1 } & \multirow[t]{2}{*}{$\mathrm{P} 2$} & \multirow[t]{2}{*}{ P3 } \\
\hline & & No. $=30$ & No. $=30$ & No. $=30$ & & & & & & \\
\hline \multirow[t]{3}{*}{ Age } & Mean \pm S & $39.50 \pm$ & $50.17 \pm$ & $57.70 \pm$ & \multirow{3}{*}{$\begin{array}{c}20.177 \\
\bullet\end{array}$} & \multirow[t]{3}{*}{0.000} & \multirow[t]{3}{*}{$\mathrm{HS}$} & \multirow{3}{*}{$\begin{array}{c}0.00 \\
0\end{array}$} & \multirow{3}{*}{$\begin{array}{c}0.00 \\
0\end{array}$} & \multirow{3}{*}{$\begin{array}{c}0.01 \\
0\end{array}$} \\
\hline & $\mathrm{D}$ & 15.24 & 11.16 & 4.04 & & & & & & \\
\hline & Range & $22-76$ & $14.00-66$ & $52-66$ & & & & & & \\
\hline \multirow[t]{2}{*}{ Gender } & Females & $16(53.3 \%)$ & $10(33.3 \%)$ & $3(10.0 \%)$ & \multirow{2}{*}{$\begin{array}{c}12.923 \\
*\end{array}$} & \multirow[t]{2}{*}{0.002} & \multirow[t]{2}{*}{ HS } & \multirow{2}{*}{$\begin{array}{c}0.11 \\
8\end{array}$} & \multirow{2}{*}{$\begin{array}{c}0.00 \\
0\end{array}$} & \multirow{2}{*}{$\begin{array}{c}0.02 \\
8\end{array}$} \\
\hline & Males & $14(46.7 \%)$ & $20(66.7 \%)$ & $27(90.0 \%)$ & & & & & & \\
\hline \multirow{3}{*}{$\begin{array}{l}\text { Weight } \\
\text { (kg) }\end{array}$} & Mean $\pm S$ & $77.17 \pm$ & $80.40 \pm$ & $76.20 \pm$ & \multirow[t]{3}{*}{$1.042 \bullet$} & \multirow[t]{3}{*}{0.357} & \multirow[t]{3}{*}{ NS } & \multirow{3}{*}{$\begin{array}{c}0.29 \\
2\end{array}$} & \multirow{3}{*}{$\begin{array}{c}0.75 \\
2\end{array}$} & \multirow{3}{*}{$\begin{array}{c}0.17 \\
2\end{array}$} \\
\hline & & 13.10 & 11.10 & 11.09 & & & & & & \\
\hline & Range & $50-105$ & $40-103$ & $60-100$ & & & & & & \\
\hline
\end{tabular}

NS: Non significant; S: Significant; HS: Highly significant

*:Chi-square test; $\bullet$ : One Way ANOVA test

P1: Comparison between control group and ESLD without renal impairment

P2: Comparison between control group and ESLD with renal impairment

P3: Comparison between ESLD without and with renal impairment

The previous table shows that there was statistically significant difference between the studied groups regarding age and gender, while no statistically significant difference between them regarding weight. 
Table (2): Comparison between ESLD patients with renal impairment group and ESLD patients without renal impairment group as regards ascites, SBP and kidneys by US

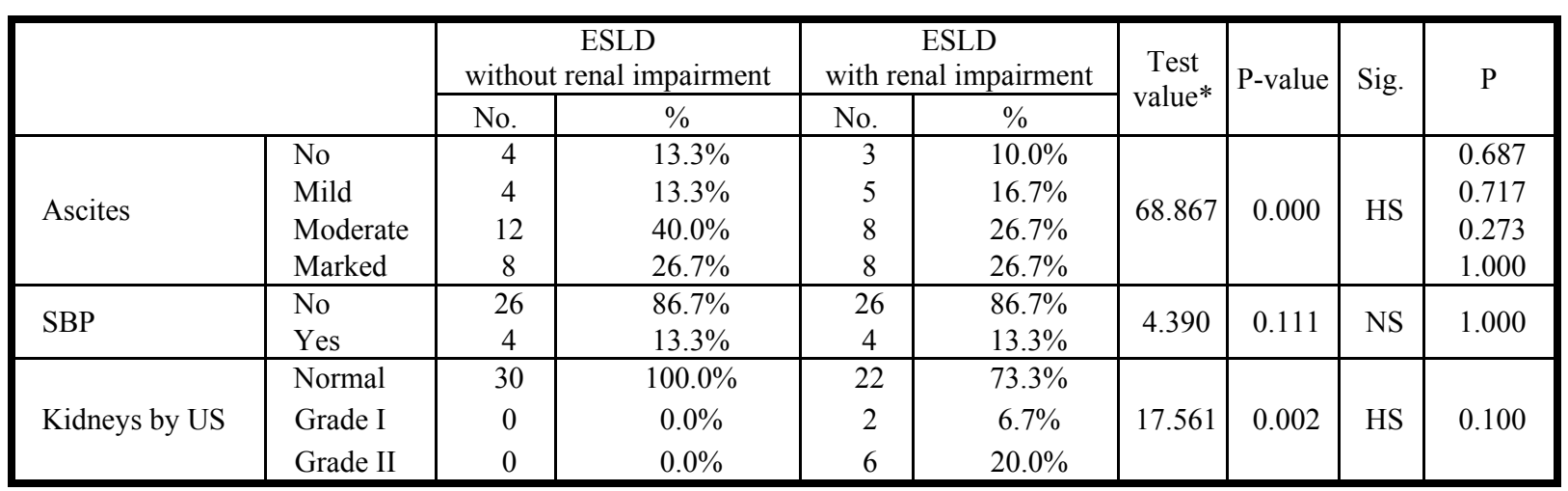

NS: Non significant; S: Significant; HS: Highly significant $\quad *$ :Chi-square test

The table shows that there was statistically significant difference between patient with renal impairment and patients without renal impairment as regards ascites and sonographic appearance of the kidneys by $\mathrm{U} / \mathrm{S}$, while no statistically significant deference regarding SBP.

Table (3): Comparison between control group and patients subgroups regarding cystatin C level

\begin{tabular}{|c|c|c|c|c|c|c|c|c|c|}
\hline \multirow[t]{2}{*}{$\begin{array}{c}\text { Cystatin C } \\
\text { (ug/l) }\end{array}$} & $\begin{array}{l}\text { Control } \\
\text { group }\end{array}$ & $\begin{array}{c}\text { ESLD } \\
\text { without renal } \\
\text { impairment } \\
\end{array}$ & $\begin{array}{c}\text { ESLD } \\
\text { with renal } \\
\text { impairment }\end{array}$ & \multirow[t]{2}{*}{$\begin{array}{c}\text { Test } \\
\text { value }\end{array}$} & \multirow[t]{2}{*}{ P-value } & \multirow[t]{2}{*}{ Sig. } & \multirow[t]{2}{*}{ P1 } & \multirow[t]{2}{*}{$\mathrm{P} 2$} & \multirow[t]{2}{*}{ P3 } \\
\hline & No. $=30$ & No. $=30$ & No. $=30$ & & & & & & \\
\hline Median(IQR) & $2.861(1.72-5.996)$ & $1.1525(0.47-1.64)$ & $0.66(0.44-1.20)$ & \multirow[t]{2}{*}{23.266} & \multirow[t]{2}{*}{0.000} & \multirow[t]{2}{*}{ HS } & \multirow[t]{2}{*}{0.000} & \multirow[t]{2}{*}{0.000} & \multirow[t]{2}{*}{0.043} \\
\hline Range & $0.37-15.777$ & $0.3622-3.879$ & $0.346-2.679$ & & & & & & \\
\hline
\end{tabular}

The previous table shows that there was highly statistically significant difference between control group and the two patients subgroups regarding cystatin $\mathrm{C}$ level while no statistically significant difference between ESLD without and with lower in patients with renal impairment groups regarding the level of Cystatin $\mathrm{C}$.

Table (4): Comparison between ESLD patients without and with renal impairment regarding clinical scores, HCC and hepatic encephalopathy.

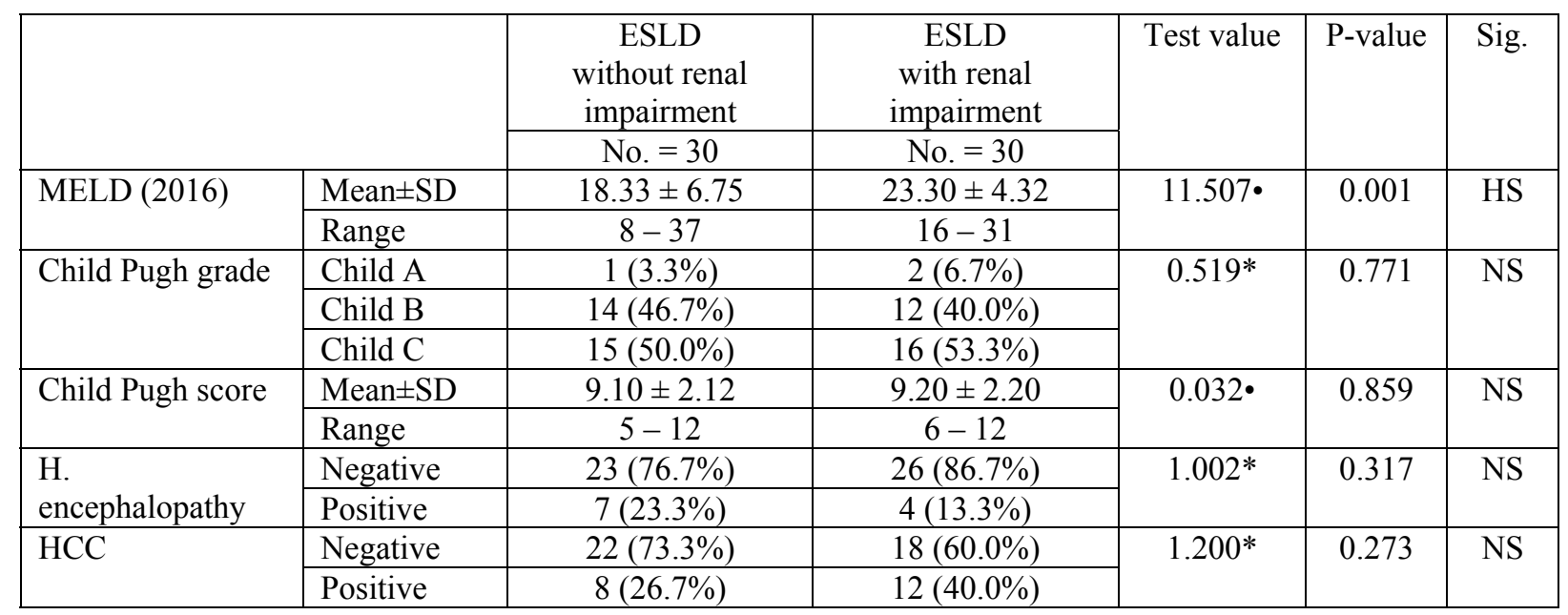

NS: Non significant; S: Significant; HS: Highly significant

*:Chi-square test; $\bullet$ : One Way ANOVA test; ł: Kruskall Wallis test 
The previous table shows that there was highly statistically significant increase in the MELD score (as expected) in patients with renal impairment than those without renal impairment while no statistically significant difference between them regarding CHILD Pugh score, hepatic encephalopathy and HCC.

\section{DISCUSSION}

Disturbed renal function is among the main complications of liver cirrhosis, frequently accompanying its later stages. It is related to poorer prognosis, especially if it has resulted from acute complications (sepsis) or has followed liver transplantation $^{(1)}$.

Renal failure complicates patients with liver disease. It varies from AKI to CKD. Renal failure is a challenging complication of liver cirrhosis, this is primarily related to reduction in systemic vascular resistance due to splanchnic vasodilatation triggered by portal hypertension also in some patients, with cirrhosis, intrinsic renal diseases may be present that are related not to alternations in systemic hemodynamics but rather to etiological factors underlying the liver disease such as glomerulonephritis associated with hepatitis B or hepatitis C infection $^{(11)}$.

The traditional laboratory approach for detection of renal deterioration does not allow for early detection of renal impairment. It needs serial measurements of serum creatinine concentrations at different time which can lag detection of AKI early before complications arise.

Our study included 90 candidates, 60 patients with End Stage Liver Disease (ESLD), whom were further divided into group I of 30 patients ESLD, with renal impairment (defined as: Cr.clearance $<60$ $\mathrm{ml} / \mathrm{min}$ ) and group II of 30 patients ESLD, without renal impairment, and a third group of 30 healthy persons.
Candidates included in our study were 61 males and 29 females $(\mathrm{M}: \mathrm{F}=2.1: 1)$ and their ages ranged from 22 to 66 yrs. Range of ages of patients in our study is almost the same in other studies such as Belcher et al. ${ }^{(12)}$ and Anas et al. ${ }^{(13)}$ studies.

These results were in contrast to Kim et al. ${ }^{(14)}$ and Hussien et al. ${ }^{(15)}$ studies in which; mean ALT level was $67.6 \pm 81.1$ and $61.1 \pm$ 17.6 in ESLD patients with renal impairment and $61.4 \pm 81.4$ and $59.1 \pm 18.3$ in ESLD patients without renal impairment.

But these results were not compatible to Hussien et al. ${ }^{(15)}$ study in which; mean bilirubin level was $1.24 \pm 0.4$ in ESLD patients with renal impairment and $1.31 \pm$ 0.4 in ESLD patients without renal impairment.

Albumin level was found to be significantly lower in ESLD patients with and without renal impairment (mean $\pm \mathrm{SD}=$ $2.25 \pm 0.46$ and $1.97 \pm 1.28$, respectively) in comparison to control group (mean $\pm \mathrm{SD}=$ $3.95 \pm 1.06$ ). It was also significantly lower in ESLD patients without renal impairment in comparison to ESLD patients with renal impairment.

These results were in contrast to Kim et al. ${ }^{(14)}$ and Hussien et al. ${ }^{(15)}$ studies in which; mean albumin level was $2.9 \pm 0.4$ and $2.7 \pm$ 0.5 in ESLD patients with renal impairment and $2.8 \pm 0.4$ and $2.5 \pm 0.6$ in ESLD patients without renal impairment.

In our study, Creatinine clearance was found to be significantly lower in ESLD patients with and without renal impairment (median [Range] $=42.5$ [35-48] and 99.5 [66-124], respectively) in comparison to control group (median [Range] $=117$ [110134]). It was also significantly lower in ESLD patients with renal impairment in comparison to ESLD patients without renal impairment.

In our study, Cystatin C level was found to be significantly lower in ESLD patients with and without renal impairment (median 
[Range $]=0.66[0.346-2.679]$ and 1.1525 [0.3622-3.879], respectively) in comparison to control group (median [Range] $=2.861$ [0.37-15.777]). It was also significantly lower in ESLD patients with renal impairment in comparison to ESLD patients without renal impairment.

However Kim et al. ${ }^{(14)}$ found that mean Cystatin C level was $1.3 \pm 0.3$ in ESLD patients with renal impairment and $1.0 \pm 0.2$ in ESLD patients without renal impairment.

These results of decreased Cystatin $\mathrm{C}$ level in patients with renal impairement can be explained by the fact that Cystatin $\mathrm{C}$ is a better marker of the glomerular filtration rate and hence of kidney function than creatinine, which is the most commonly used measure of kidney function ${ }^{(9)}$.

In the current study, MELD score was found to be significantly higher in ESLD patients with renal impairment (mean \pm SD $=23.30 \pm 4.32)$ in comparison to ESLD patients without renal impairment (mean \pm $\mathrm{SD}=18.33 \pm 6.75$ )

These results were in consistent with Kim et al. ${ }^{(14)}$ study in which; mean MELD score was $22.1 \pm 13.3$ in ESLD patients with renal impairment and $20.5 \pm 11.0$ in ESLD patients without renal impairment.

These results regarding higher MELD score in ESLD patients with renal impairment in comparison to ESLD patients without renal impairment can be explained by the fact that MELD score is a scoring system for assessing the severity of chronic liver disease that includes creatinine level as a parameter. It was initially developed to predict mortality within three months of surgery in patients who had undergone a transjugular intrahepatic portosystemic shunt (TIPS) procedure ${ }^{(16)}$, and was subsequently found to be useful in determining prognosis and prioritizing for receipt of a liver transplant ${ }^{(17)}$.

The comparison between ESLD patients with or without renal impairment and control group regarding Cystatin $\mathrm{C}$ level revealed that the best cut off value was found to be $\leq$ $169 \mathrm{mg} / 1$ with area under the curve (AUC), 0.800; Sensitivity, $88.3 \%$; Specificity, $80 \%$; Positive predictive value (PPV), 89.8\%; Negative predictive value (NPV), 77.4\%.

On the other hand, the comparison between ESLD patients with or without renal impairment and control group regarding creatinine clearance level revealed that the best cut off value was found to be $\leq$ $90 \mathrm{ml} / \mathrm{min}$ with area under the curve (AUC), 0.848; Sensitivity, 71.67\%; Specificity, $100.00 \%$; Positive predictive value (PPV), $100.0 \%$; Negative predictive value (NPV), $63.8 \%$.

\section{Conclusion}

Creatinine clearance was found to be significantly lower in ESLD patients with and without renal impairment in comparison to control group. It was also significantly lower in ESLD patients with renal impairment in comparison to ESLD patients without renal impairment. Cystatin C level was found to be significantly lower in ESLD patients with and without renal impairment in comparison to control group. It was also significantly lower in ESLD patients with renal impairment in comparison to ESLD patients without renal impairment. The comparison between ESLD patients with or without renal impairment and control group regarding Cystatin $\mathrm{C}$ level revealed that the best cut off value was found to be $\leq 169$ $\mathrm{mg} / \mathrm{l}$ with area under the curve (AUC), 0.800 ; Sensitivity, $88.3 \%$; Specificity, $80 \%$; Positive predictive value (PPV), $89.8 \%$; Negative predictive value (NPV), 77.4\%. As for the comparison between ESLD patients with or without renal impairment and control group regarding creatinine clearance level revealed that the best cut off value was found to be $\leq 90 \mathrm{ml} / \mathrm{min}$ with area under the curve (AUC), 0.848; Sensitivity, 71.67\%; Specificity, $100.00 \%$; Positive predictive value (PPV), 100.0\%; Negative predictive value (NPV), $63.8 \%$. 


\section{REFERENCES}

1. Gonwa TA, McBride MA, Anderson $\mathrm{K}$ et al. (2006): Continued influence of preoperative renal function on outcome of Orthotopic Liver Transplant (OLTX) in the US: where will MELD lead us? Am J Transplant., 6:2651-6.

2. Garcia-Tsao G, Parikh $\mathrm{C}$ and Viola A (2008): Acute kidney injury in cirrhosis. Hepatology, 48:2064-2077.

3. Wong F, Nadim M, Kellum J et al. (2011): Working Party proposal for a revised classification system of renal dysfunction in patients with cirrhosis. Gut, 60:702-709.

4. Moreau R and Lebrec D (2007): Diagnosis and treatment of acute renal failure in patients with cirrhosis. Best Pract Res Clin Gastroenterol., 1:111-23.

5. Grigorov N (2010): Abdominal Doppler ultrasonography. ZIP: Sofi a., 98-100.

6. Sherman D, Fish D and Teitelbaum I (2003): Assessing renal function in cirrhotic patients: problems and pitfalls. Am J Kidney Dis., 41:269-278.

7. Stevens LA, Coresh J, Greene $\mathrm{T}$ et al. (2006): Assessing kidney function measured and estimated glomerular filtration rate. N Eng J Med., 354:2473-83.

8. Bilyana L and Teneva H (2012): Pathogenesis and assessment of renal function in patients with liver cirrhosis. Folia Medica., 54(4):5-13.

9. Dharnidharka VR, Kwon C, Stevens G (2002): Serum cystatin C is superior to serum creatinine as a marker of kidney function: a meta-analysis. Am J Kidney Dis., 40:221-6.
10. Chung MY, Jun DW, Sung SA (2010): Diagnostic value of cystatin $\mathrm{C}$ for predicting acute kidney injury in patients with liver cirrhosis. The Korean Journal of Hepatology, 16:301-7.

11. Bosch J, Abraldes J, Berzigotti A et al. (2008): Portal hypertension and gastrointestinal bleeding. Semin Liver Dis., 28:325.

12. Belcher J, Arun J, Aldo J et al. (2014): Kidney Biomarkers and Differential Diagnosis of Patients With Cirrhosis and Acute Kidney Injury. Hepatology, 60(2): 622-632.

13. Anas A, Salama F, Emad H et al. (2014): Urinary Biomarkers of Acute Kidney Injury in Patients with Liver Cirrhosis. ISRN Nephrology, 2014 : 376795.

14. Kim DJ, Kang HS, Choi HS et al. (2011): Serum Cystatin C level is a useful marker for the evaluation of renal function in patients with cirrhotic ascites and normal serum creatinine levels. The Korean Journal of Hepatol., 17:130-138.

15. Hussien HI, Shahen NE, Atiyah MW et al. (2012): Serum Cystatin C is Superior to Serum Creatinine for Detection of Acute Kidney Injury in Cirrhotic Patients with Upper Gastrointestinal Bleeding. Med. J. Cairo Univ., 80 (1): 857-863.

16. Malinchoc M, Kamath PS, Gordon FD et al. (2000): A model to predict poor survival in patients undergoing transjugular intrahepatic portosystemic shunts. Hepatol., 31(4):864-71.

17. Kamath PS and Kim WR (2007): The model for end - stage liver disease (MELD). Hepatol., 45 (3): 797-805. 


\section{الملخص الـعربي}

برتبط تليف الكبد مع ارتفاع معدلات المرض ومعدلات الوفيات بشكل كبير. قصور وظائف الكلى هي من بين بين

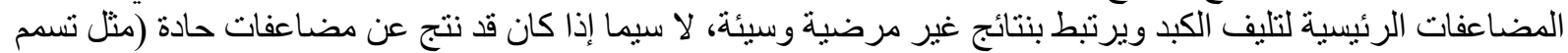
الدم) أو مابعد زر اعة الكبد.

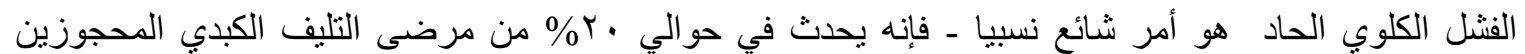

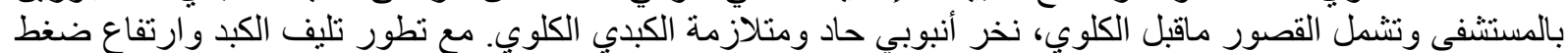

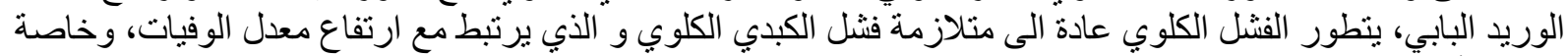

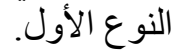

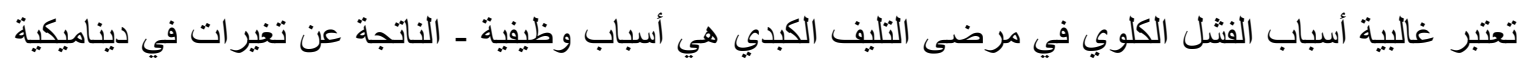

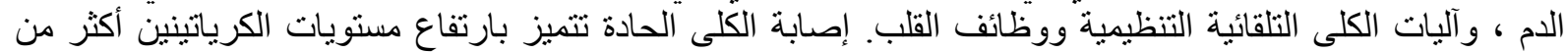

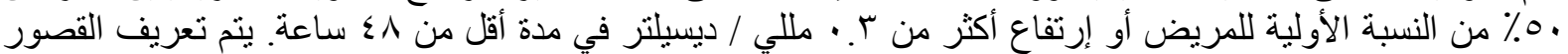

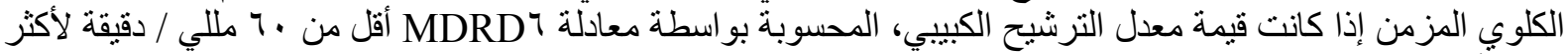
من ب أثنهر.

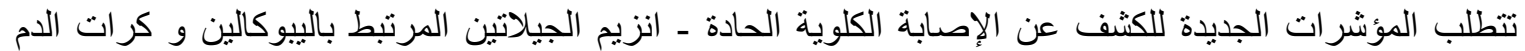

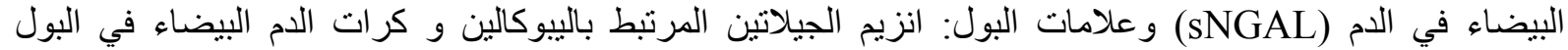

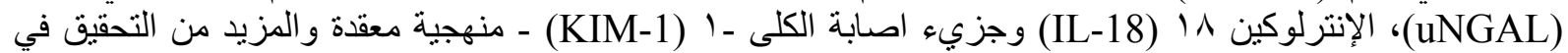

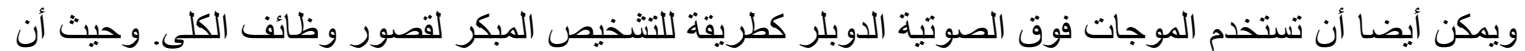

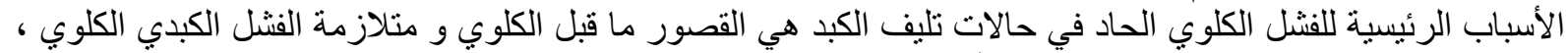

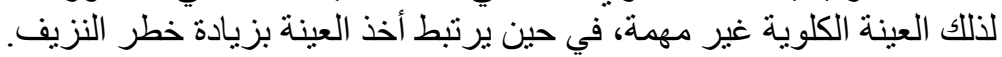

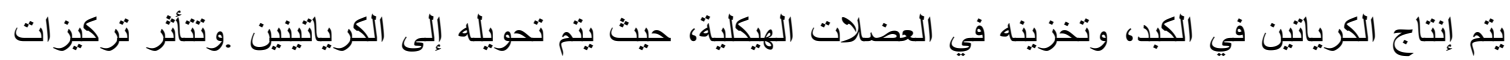

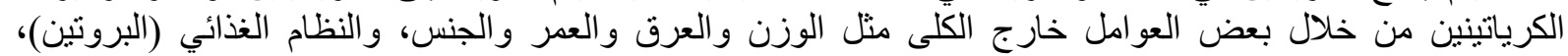
و التحول من الكرياتين في الكرياتينين، ومسنوى الماء، فضلا عن تخزين الكائن الحي للكرياتين (كتلة العضلات بشكل عام).

السيستاتين سي هو بروتين منخفض الوزن الجزيئي (با.با كيلو دالتون)، وهو ممثل لمثبطات الأنزيم البروتيني-

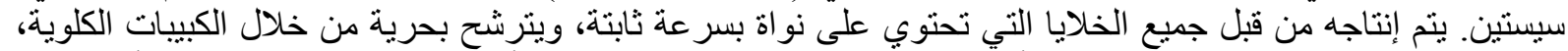

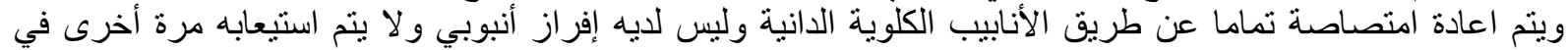

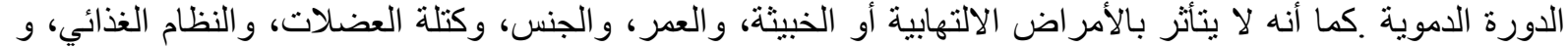

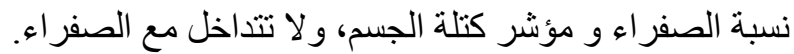

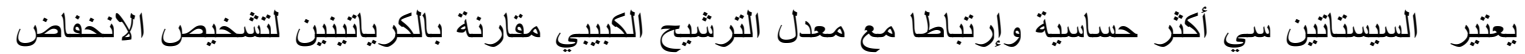

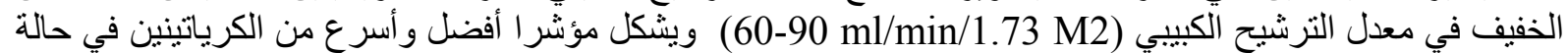

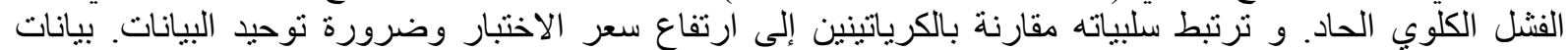

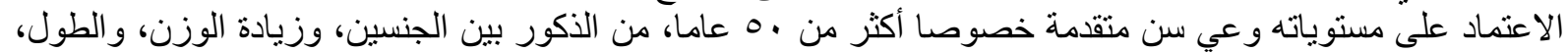

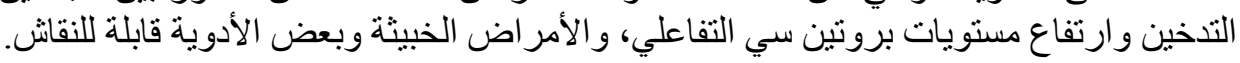

الهذف من العمل

تقييم دور السيستاتين سي كمؤشر حيوي لقصور وظائف الكلى في المرضى الذين يعانون من تليف الكبد المتقدم. 